\title{
PEMBERDAYAAN KELOMPOK USAHA MASYARAKAT PADA OBJEK WISATA ALAM DI KELURAHAN KAMBO KECAMATAN MUNGKAJANG KOTA PALOPO
}

\author{
Muh. Halim ${ }^{1}$, Saharuddin ${ }^{2}$ \\ Sekolah Tinggi Ilmu Ekonomi Muhammadiyah Palopo \\ ${ }^{1}$ E_Mail: halimpalatte@gmail.co.id
}

\begin{abstract}
Abstrak: Tujuan progam KKN-PPM ini adalah peningkatan pengetahuan, sikap dan keterampilan masyarakat untuk memanfaatkan potensi objek wisata alampada Kelurahan Kambo Kecamatan Mungkajang Kota Palopo sebagai mata pencaharian dan sumber pendapatan keluarga. Melakukan pembinaan dan pendampingan dalam menyiapkan berbagai fasilitas pendukug objek wisata alam, baik pada aspek teknis maupun aspek manajemen secara komprehenship.

Target khusus progam KKN-PPM ini adalah berupa pembuatan gazebo pada lokasi strategis, menyiapkan fasilitas pendukung yang berdampak pada penumbuhan jiwa entrepreneurship anggota kelompok usaha jasa wisata, peningkatan wawasan dan pengetahuan tentang pentingnya berusaha, peningkatan pengetahuan tentang manajemen pemasaran jasa wisata, sehingga terjalin kerjasama yang memberikan manfaat terhadap peningkatan ekonomi masyarakat secara berkelanjutan.

Metode yang digunakan dalam progam KKN-PPM ini adalah pendampingan dan penyuluhan dalambentuk pelatihan pembuatan gazebo pada lokasi objek wisata alam yang strategis. Selain itu dilakukan pembinaan manajemen kerjasama antar kelompok yang saling menguntungkan. Adapun rencana kegiatan progam KKN-PPM, meliputi: (a) sosialisasi program KKN-PPM untuk menyatukan persepsi tim pengusul dengan mitra, (b) penyiapan sarana dan prasarana yang mendukung pelaksanaan kegiatan, (c) penyiapan peralatan dan introduksi peralatan yang dirancang dan dilaksanakan oleh timpengusul, $(d)$ peningkatan penge tahuan dan keterampilan mitra melalui pelatihan (penguatan jiwa entrepreneurship, pelatihan pembuatan gazebo, pelatihan penggunaan dan perawatan objek-objek wisata alam, pelatihan manajemen pemasaran jasa wisata, (e) operasionalisasi program KKN-PPM dan (f) monitoring dan evaluasi program untuk menjamin keberlanjutan dan pengembangan program KKN-PPM di masa yang akan datang.
\end{abstract}

Keyword: Pemberdayaan, Objek wisata alam dan Kelompok usaha

\section{PENDAHULUAN}

Kelurahan Kambo merupakan salah satu kelurahan yang berada di Kecamatan Mungkajang Kota Palopo. Luas wilayah kelurahan Kambo $11,42 \mathrm{~km} 2$ berada di atas ketinggian antara 100 sampai $490 \mathrm{dpl}$ pada wilayah pemukiman penduduk. Sedangkan wilayah kebun penduduk berada antara 500 sampai $1.281 \mathrm{dpl}$.

Sebelah Utara kelurahan Kambo berbatasan langsung dengan kelurahan Battang, sebelah Selatan berbatasan dengan kelurahan Latuppa, sebelah Timur berbatasan dengan kelurahan Mungkajang, dan sebelah Barat berbatasan dengan Kabupaten Tana Toraja.
Jarak antara Kota Palopo ke lokasi objek wisata Kambo sekitar $10 \mathrm{~km}$ dengan waktu tempu mencapai antara 10 sampai 15 menit. Waktu tempu tersebut sangat dipengaruhi oleh keahlian mengemudi kendaraan karena kondisi jalan raya yang terjal, sempit, dan licit pada musim hujan. Kelurahan Kambo memiliki tiga rukun wilayah (RW) dan sembilan rukun tetangga dengan jumlah penduduk 1.026 jiwa terdiri atas laki-laki sebanyak 542 jiwa dan perempuan sebanyak 484 jiwa. Penduduk kelurahan Kambo menganut agama Islam, sehingga memiliki tiga bangunan masjid permanen. Sumber dana pembangunan Masjid tersebut berasal dari swadaya penduduk setempat dan ada juga sumbangan pemerintah. Rumah penduduk Kambo berada di sisi kiri kanan jalan 
dan sebagian besar terbuat dari kayu dan sebagian kecil sudah permanen.

Pekerjaan penduduk Kambo sebagian besar sebagai petani cengkeh, kakao, merica, dan lada. Luas lahan produktif mencapai 1.142 ha. Penduduk juga memiliki lahan sekitar rumah untuk ditanami rempa-rempa hasil bumi, seperti selei, lengkuas, patikala, jahe, dan kunyit. Penduduk setempat tidak bisa menanam sayur mayur karena banyak hama, terutama babi hutan yang sangat banyak. Daerah Kambo sudah dikenal sebagai pemasok serei, lengkuas, dan patikala setiap hari kepada pemilik usaha rumah makan dan katering yang ada di Kota Palopo dan daerah sekitarnya.

Kelurahan Kambo memiliki 15 kelompok tani (poktan) dengan jumlah anggota sebanyak 225 orang. Pemerintah Kota Palopo memberikan bantuan berupa bibit unggul, pupuk, dan tenaga penyuluh pertanian. Penduduk Kambo juga memiliki satu kelompok kerajinan (industri rumah tangga) dalam bentuk pembuatan kripik pisang dan pembuatan gula merah yang terbuat dari air nira atau enau. Kelurahan Kambo juga menghasilkan buah-buahan yang bersifat musiman, seperti durian, langsat, mangga, dan rambutan. Jenis unit usaha yang ada di Kambo yaitu satu unit warung dan 14 unit kios yang menyediakan kebutuhan sehari-hari penduduk setempat.

Kelurahan Kambo sudah menikmati aliran listrik PT. PLN cabang Palopo, air mengalir non stop dari atas gunung langsung masuk ke rumah penduduk dengan menggunakan pipa paralon atau slang plastik serta sudah dapat signal satelit untuk handpone sehingga mempermudah komunikasi dengan pihak luar.
Kelurahan Kambo memiliki karakteristik berupa keindahan alam, udara sejuk, masyarakat yang ramah, dan lingkungan yang aman. Salah satu potensi yang dapat dikembangkan pada kelurahan Kambo adalah objek wisata alam. Sementara itu di Kelurahan Kambo memiliki sarana jalan raya yang sudah di aspal, udaranya sejuk, pemandangannya indah, penghasil buahbuahan, serta memiliki kelompok usaha kerajinan.

Di Kelurahan Kambo Kecamatan Mungkajang Kota Palopo juga terdapat kelompok usaha yang bergerak dibidang usaha kecil mikro yang menghasilkan beberapa produk kerajinan, warung, dan kios, sebagai faktor penunjang wisata alam di kelurahan kambo. Objek wisata alam sangat potensial untuk dikembangkan melalui peran serta masyarakat dengan cara dibekali pengetahuan dan keterampilan untuk menyediakan tempat-tempat istirahat bagi wisatawan. Objek wisata alam sangat indah pemandangannya, baik di waktu siang dan malam hari sambil menikmati makanan ringan yang disiapkan oleh masyarakat setempat. Makanan ringan dimaksud, seperti kripik pisang, secangkir kopi, sarabba, pisang goreng, buah-buahan hasil kebun dan sebagainya.

Sebagian besar masyarakat di Kelurahan Kambo memiliki pekerjaan sebagai petani ladang dan sebagian kecil sebagai pedagang cengkeh, coklat, dan buah-buahan serta pegawai negeri atau karyawan swasta. Mata pencaharian penduduk setempat mendukung aktivitas pelatihan pembuatan sarana dan pra sarana penunjang objek wisata alam yang dibutuhkan oleh pengunjung. Cara pembuatan sarana dan prasarana berupa gazebo (tempat istirahat wisatawan). Selain itu, masyarakat juga memproduksi berbagai makanan 
ringan yang dihasilkan sendiri oleh penduduk setempat. Semua hasil karya masyarakat di Kelurahan Kambo, baik jasa maupun barang sebagai mata pencaharian yang potensial dan akan meningkatkan pendapatan keluarga.

Letak geografis kelurahan kambo sangat mudah dijangkau karena berada di atas lereng gunung menghadap ke Kota Palopo, sehingga nampak keindahan kota di siang hari terutama di malam hari. Nampak kelap kelip lampu jalan dan lampu pemukiman masyarakat. Suhu udara kambo terasa sejuk pada waktu sepanjang hari terutama pada waktu sore sampai pagi hari yang mencapai suhu udara 15 derajat selcius. Selain itu, kelurahan kambo memiliki keunggulan, karena daerah ini memiliki beberapa jenis buah-buahan, bumbu masak hasil kebun dan kue-kue buatan kelompok usaha tani.

Metode penerapan pembuatan gazebo sebagai tempat wisatawan beristirahat yaitu melakukan pemberdayaan berupa pelatihan dan pendampingan mengenai cara membuat gazebo yang menarik, aman dan nyaman, serta memberikan nilai tambah kepada masyarakat setempat. Mendirikan gazebo pada lokasi yang strategis, yaitu lokasi yang memiliki pemandangan bebas ke Kota Palopo dan sekitarnya.

Mitra dalam program KKN-PPM ini adalah objek wisata permandian alam di Kelurahan Latuppa Kecamatan Mungkajang Kota Palopo, terdiri atas permandian alam air terjun dan permandian alam kali jodoh. Bentuk pelatihan dan pembinaan masyarakat terhadap pembuatan fasilitas gazebo sebagai penunjang objek wisata alam dan memberikan pelayanan yang menarik kepada wisatawan.

\section{METODE DAN BAHAN}

\section{Persiapan dan Pembekalan}

Mekanisme pelaksanaan kegiatan pemberdayaan kelompok usaha jasa wisata, berupa pelatihan dan pendampingan dapat dilihat pada Gambar 1 sebagai berikut:

Mekanisme Pelatihan dan Pendampingan objek wisata alam Kambo

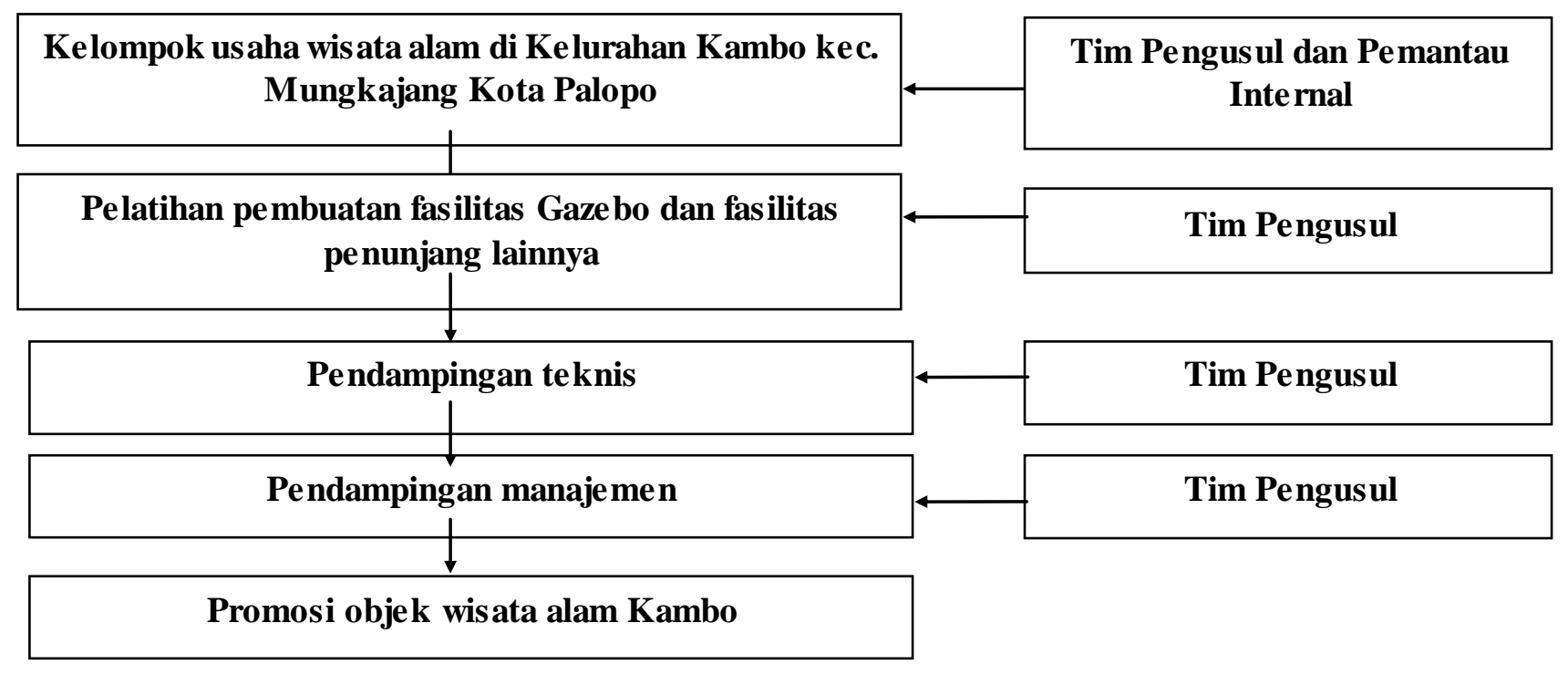




\section{Pelaksanaan}

Langkah-langkah dan metode yang akan dilakukan dalam pelaksanaan program KKN-PPM ini adalah sebagai berikut:

1. Melakukan sosialisasi program KKN-PPM untuk menyatukan persepsi tim pengusul dan mitra dalam pelaksanaan pelatihan dan pendampingan.

Sosialisasi program KKN-PPM bertujuan untuk mendapatkan respon atau tanggapan masyarakat setempat sebagai mitra dalam kesiapannya mengikuti pelatihan pendirian gazebo di wilayah kelurahan Kambo. Respon masyarakat sangat mendukung program mahasiswa yaitu mendirikan gazebo sebagai fasilitas penunjang objek wisata. Mahasiswa bersama mitra sepakat untuk pelaksanaan pelatihan atau workshop pada hari jumat pagi setelah kerja bakti (jumat bersih). Melalui pelatihan diperkenalkan pentingnya gazebo dalam menunjang objek wisata. Selain itu, gazebo dapat memberikan nilai tambah ekonomi, sebagai tempat transaksi dan menambah pendapatan masyarakat setempat.

2. Penyiapan sarana dan prasarana pendukung pelaksanaan pendirian gazebo.

Penyiapan sarana dan prasarana pendukung pelaksanaan pendirian gazebo dibebankan kepada mitra, berupa; penyediaan lokasi, tenaga kerja, dan beberapa material atau bahan. Lokasi pendirian gazebo cukup banyak yang sangat strategis, namun tidak semua bisa ditempati mendirikan gazebo karena pemilik lahan tersebut tidak bersedia memberikan. Perlu diketahui, bahwa harga lahan di tepi jalan raya di Kelurahan Kambo sudah mulai mahal, sehingga lokasi pendirian gazebo sangat terbatas.

Tenaga kerja terampil yang mampu mengerjakan dan mendirikan gazebo sesuai desain, sangat terbatas dan ada yang meminta upah kerja. Mahasiswa melakukan pendekatan dengan seorang tukang kayu untuk bersedia membantu membangun gazebo dengan upah yang sangat murah. Gazebo dikerja termasuk lama, karena hanya dikerjakan pada waktu sore hari sekitar dua sampai tiga jam.

3. Peralatan dan bahan yang dibutuhkan untuk mendirikan gazebo

Jenis peralatan yang digunakan untuk mendirikan gazebo, seperti gergaji, pahat, skap, parang, dan sebagainya. Semua peralatan yang dipakai, disiapkan oleh tukang. Sedangkan bahan yang dibutuhkan untuk mendirikan gazebo sebagian besar disiapkan oleh tim pengusul dan sebagian kecil disiapkan oleh mitra. Jenis bahan yang dibutuhkan untuk mendirikan gazebo, seperti papan, balok, bambu, paku, dan atap.

4. Melakukan desain dan pemilihan lokasi pendirian gazebo merupakan tahap penentu keberhasilan program KKN-PPM.

Desain atau gambar gazebo dilakukan oleh mahasiswa KKN bersama kelompok masyarakat sebagai mitra. Desain tersebut ada dua bentuk yaitu (1) gazebo berbentuk bundar pada atap dan tempat duduk dan (2) gazebo berbentuk persegi empat. Setelah didiskusikan ke dua tim, maka disepakati memilih gazebo berbentuk persegi empat 
dengan alasan bahwa; dapat menghemat bahan, hemat biaya, mudah dikerjakan, dan menggunakan lokasi yang sempit. Setelah desain gazebo disepakai bentuknya, maka rencana selanjutnya adalah memilih lokasi pendirian gazebo. Beberapa faktor penunjang adalah lokasi gazebo harus dekat dengan rumah penduduk agar : (1) gazebo dapat dijaga pemanfaatannya. (2) dekat pasokan listrik dari rumah penduduk. (3) ada yang bertanggungjawab terhadap kebersihan gazebo. (4) ada yang menagih sewa jasa gazebo.

5. Peningkatan pengetahuan dan keterampilan mitra melalui pelatihan, antara lain:

a. Penguatan jiwa entrepreneurship pada semua peserta

b. Pelatihan teknis pembuatan gazebo pada lokasi strategis (pemandangan terbuka)

c. Pelatihan pemanfaatan gazebo di lokasi objek wisata alam

d. Pelatihan manajemen objek wisata dan kerjasama dengan pihak swasta serta pemerintah daerah setempat.

6. Monitoring dan evaluasi program sebagai bentuk tindak lanjut pengembangan program KKN-PPM.

Pelaksanaan kegiatan KKN-PPM ini telah berlangsung dengan baik melalui kerjasama dan partisipasi aktif dari mitra. Selain partisipasi sebagai kelompok sasaran atau peserta dalam pelatihan yang telah dilaksanakan pada program ini. Partisipasi mitra dalam hal menyediakan alat dan bahan untuk mengerjakan gazebo di lokasi yang strategis (pemandangan terbuka).

\section{HASIL DAN PEMB AHASAN}

Program KKN-PPM pengabdian kepada masyarakat yang diselenggarakan oleh Mahasiswa bersama Dosen Pembimbing STIE Muhammadiyah Palopo. Program KKN-PPM pengabdian yang difasilitasi oleh pimpinan institusi memberikan dana sebesar Rp 5 juta untuk melakukan program tersebut. Dana awal diperoleh sebesar $15 \%$ dari Rp 5 juta atau Rp 1,5 juta dipakai untuk membiayai tahapan kegiatan sesuai jadwal, mulai sosialisasi, workshop, dan pembelian mahan untuk gazebo.

Sebelum mendirikan sarana gazebo, maka pelaksana kegiatan melakukan observasi pada lokasi yang tepat untuk mendirikan gazebo. Setelah menentukan lokasi gazebo, maka tindakan selanjutnya yaitu melakukan sosialisasi program KKN-PPM kepada masyarakat yang bertujuan untuk mendapatkan respon atau tanggapan masyarakat setempat sebagai mitra dalam kesiapannya mengikuti pelatihan pendirian gazebo di wilayah kelurahan Kambo. Respon masyarakat sangat mendukung program mahasiswa yaitu mendirikan gazebo sebagai fasilitas penunjang objek wisata. Mahasiswa bersama mitra sepakat untuk pelaksanaan pelatihan atau workshop pada hari jumat pagi setelah kerja bakti (jumat bersih). Melalui pelatihan diperkenalkan pentingnya gazebo dalam menunjang objek wisata. Selain itu, gazebo dapat berfungsi ganda sebagai tempat transaksi, memberikan nilai tambah ekonomi, dan menambah pendapatan masyarakat setempat.

\section{Persiapan Bahan dan Peralatan}

Penyiapan bahan dan peralatan pendukung pendirian gazebo dibebankan kepada mitra, 
berupa; penyediaan lokasi, tenaga kerja, dan beberapa material atau bahan. Lokasi pendirian gazebo cukup banyak yang sangat strategis, namun tidak semua bisa ditempati mendirikan gazebo karena pemilik lahan tersebut tidak bersedia memberikan. Perlu diketahui, bahwa harga lahan di tepi jalan raya di Kelurahan Kambo sudah mulai mahal, sehingga lokasi pendirian gazebo sangat terbatas.

Tenaga kerja terampil yang mampu mengerjakan dan mendirikan gazebo sesuai desain, sangat terbatas dan ada yang meminta upah kerja. Mahasiswa melakukan pendekatan dengan seorang tukang kayu untuk bersedia membantu membangun gazebo dengan upah yang sangat murah. Gazebo dikerja termasuk lama, karena hanya dikerjakan pada waktu sore hari sekitar dua sampai tiga jam.

Jenis peralatan yang digunakan untuk mendirikan gazebo, seperti gergaji, pahat, skap, parang, dan sebagainya. Semua peralatan yang dipakai, disiapkan oleh tukang. Sedangkan bahan yang dibutuhkan untuk mendirikan gazebo sebagian besar disiapkan oleh tim pengusul dan sebagian kecil disiapkan oleh mitra. Jenis bahan yang dibutuhkan untuk mendirikan gazebo, seperti papan, balok, bambu, paku, dan atap.

Desain gazebo dilakukan oleh mahasiswa KKN bersama kelompok masyarakat sebagai mitra. Desain tersebut ada dua bentuk yaitu (1) gazebo berbentuk bundar pada atap dan tempat duduk dan (2) gazebo berbentuk persegi empat. Setelah didiskusikan ke dua tim, maka disepakati memilih gazebo berbentuk persegi empat dengan alasan bahwa; dapat menghemat bahan, hemat biaya, mudah dikerjakan, dan menggunakan lokasi yang sempit. Setelah desain gazebo disepakai bentuknya, maka rencana selanjutnya adalah memilih lokasi pendirian gazebo yang harus dekat dengan rumah penduduk agar : (1) gazebo dapat dimanfaatkan (2) dekat pasokan listrik (3) ada yang bertanggungjawab terhadap kebersihan gazebo.

Peningkatan pengetahuan dan keterampilan mitra melalui pelatihan, antara lain:

a. Penguatan jiwa entrepreneurship pada semua peserta

b. Pelatihan teknis pembuatan gazebo pada lokasi strategis (pemandangan terbuka)

c. Pelatihan pemanfaatan gazebo di lokasi objek wisata alam

d. Pelatihan manajemen objek wisata dan kerjasama dengan pihak swasta serta pemerintah daerah setempat.

Pelaksanaan kegiatan KKN-PPM ini telah berlangsung dengan baik melalui kerjasama dan partisipasi aktif dari mitra. Selain partisipasi sebagai kelompok sasaran atau peserta dalam pelatihan yang telah dilaksanakan pada program ini. Partisipasi mitra dalam hal menyediakan alat dan bahan untuk mengerjakan gazebo di lokasi yang strategis (pemandangan terbuka).

Penyiapan pendirian gazebo dibebankan kepada mitra, berupa; penyediaan lokasi, tenaga kerja, dan beberapa material atau bahan. Lokasi pendirian gazebo cukup banyak yang sangat strategis, namun tidak semua bisa ditempati mendirikan gazebo karena pemilik lahan tersebut tidak bersedia memberikan. Perlu diketahui, bahwa harga lahan di tepi jalan raya di Kelurahan Kambo sudah mulai mahal, sehingga lokasi pendirian gazebo sangat terbatas. 
Tenaga kerja terampil yang mampu mengerjakan dan mendirikan gazebo sesuai desain, sangat terbatas dan ada yang meminta upah kerja. Mahasiswa melakukan pendekatan dengan seorang tukang kayu untuk bersedia membantu membangun gazebo dengan upah yang sangat murah. Gazebo dikerja termasuk lama, karena hanya dikerjakan pada waktu sore hari sekitar dua sampai tiga jam.

Jenis peralatan yang digunakan untuk mendirikan gazebo, seperti gergaji, pahat, skap, parang, dan sebagainya. Semua peralatan yang dipakai, disiapkan oleh tukang. Sedangkan bahan yang dibutuhkan untuk mendirikan gazebo sebagian besar disiapkan oleh tim pengusul dan sebagian kecil disiapkan oleh mitra. Jenis bahan yang dibutuhkan untuk mendirikan gazebo, seperti papan, balok, bambu, paku, dan atap.

Desain atau gambar gazebo dilakukan oleh mahasiswa KKN bersama kelompok masyarakat sebagai mitra. Desain tersebut ada dua bentuk yaitu (1) gazebo berbentuk bundar pada atap dan tempat duduk dan (2) gazebo berbentuk persegi empat. Setelah didiskusikan ke dua tim, maka disepakati memilih gazebo berbentuk persegi empat dengan alasan bahwa; dapat menghemat bahan, hemat biaya, mudah dikerjakan, dan menggunakan lokasi yang sempit. Setelah desain gazebo disepakai bentuknya, maka rencana selanjutnya adalah memilih lokasi pendirian gazebo. Beberapa faktor penunjang adalah lokasi gazebo harus dekat dengan rumah penduduk agar : (1) gazebo dapat dijaga pemanfaatannya. (2) dekat pasokan listrik dari rumah penduduk. (3) ada yang bertanggungjawab terhadap kebersihan gazebo. (4) ada yang menagih sewa jasa gazebo.

\section{SIMPULAN}

Program KKN-PPM pengabdian kepada masyarakat telah berlangsung sesuai jadwal. Program pembangunan gazebo telah selesai atas kerjasama antara kelompok mahasiswa dengan kelompok mitra. Mahasiswa KKN-PPM memfasilitasi masyarakat sebagai mitra untuk ikut berpartisipasi aktif dalam mengerjakan gazebo. Semua biaya pembangunan gazebo ditaggung oleh STIE Muhammadiyah Palopo.

Masyarakat mitra merasa terbantu atas pembangunan gazebo yang merupakan salah satu fasilitas penunjang objek wisata. Kekuatan dan peluang pengembangan objek wisata alam Kambo untuk ditingkatkan, karena lokasi objek wisata tersebut sangat mudah dijangkau dengan kendaraan roda empat dan roda dua karena jalan raya sudah di aspal. Pemandangan yang sangat indah, udara sangat sejuk sepanjang hari, dan aman.

\section{DAFTAR PUSTAKA}

Joyosuharto, Sunardi. 2001. Aspek Ketersediaan (Supply) dan tuntutan Kebutuhan (Demand) dalam Pariwisata. dalam Fandeli, Chafid (Ed). Dasar-dasar Manajemen Kepariwisataan Alam. Penerbit Liberty, Yogyakarta.

Kotler, Philip, 2003, Manajemen Pemasaran, Analisa Perencanaan dan pengendalian. Edisi Keenam, jilid II, Penerbit Erlangga, Jakarta.

Murti Sumarni \& John Soeprihanto, 1994. Pengantar Bisnis (Dasar-Dasar Ekonomi Perusahaan). Edisi Kelima, Liberty Yogyakarta.

Pendit, Nyoman S. 2004. Ilmu Pariwisata Sebuah Perdana. Penerbit Pradinya Paramita, Jakarta. 
Supriatna, Tjahya. 2003. Sistem Administrasi

Pemerintahan di Daerah. Penerbit Bumi Aksara, Jakarta.

Widjaja, HAW. 2001. Otonomi Daerah dan Daerah Otonom. Penerbit PT Raja Grafindo Persada, Jakarta.

UU No. 32 Tahun 2004 tentang Pemerintah Daerah.

UU.No.10 Tahun 2009 tentang Kepariwisataan. 